\title{
Applying the Reader-response Approach in Teaching English Short Stories to EFL Students
}

\author{
Sarvenaz Khatib \\ Allameh Tabataba'i University, Iran \\ Email: Sarvenaz_khatib@yahoo.com
}

\begin{abstract}
This article argues about the practicality of introducing the reader-response approach to teaching English literature to Iranian EFL students. The conventionally used traditional method and the newly introduced reader-response approach to teaching English short stories were implemented in two different groups of college students. It was of the interest of the researcher to observe any differences in the reading comprehension, vocabulary acquisition and motivation for further reading of English literature amongst the students of the two groups. The findings revealed that students directed with the reader-response approach could give aesthetic responses to literature without impairing their comprehension of the literary text. However, there were no significant differences revealed in the level of vocabulary acquisition or degree of motivation of the students of the two groups to read English literature in the future, deliberately and on their own.
\end{abstract}

Index Terms - the Reader-response Theory, the traditional method, aesthetic response, transaction, motivation

\section{USING LITERATURE IN EFL CLASSES}

Although the importance and efficiency of the application of literature in language teaching classes had long been neglected by language educators, language teaching researchers and theorists, there has been a new wave of inviters of literature into EFL pedagogy since the early 1980s. It is agreed by most of these supporters that there is a noticeable superiority in the numerous advantages of the use of literary texts in comparison to other teaching materials (Brumfit \& Carter, 1986; Carter \& Long, 1991; Lazar, 1993; Lazar, 1994; Duff \& Maley, 1991; Maley, 2001; McRae, 1991; Spack, 1985; Widdowson, 1975; 1984; 1992).

The availability of a generous resource of written material, the existence of fundamental and general themes shared by the majority of people of different cultures as universals, the presence of the potential to be related to by readers and to be associated with personal thoughts, emotions and experiences, the genuine authenticity of it and the vivid illustration of the lifestyles, cultures, beliefs and behaviours of the people of the target society are only some of the numerous and immeasurable advantages of using literature in EFL contexts.

However, The most significant reason for using literature in EFL classes is that through reading it, readers are emotionally and personally involved with the text and the characters, a fact that can distant learners from the merely mechanical ordeal of language learning. Using literature in teaching a target language can provide an enjoyable and yet equally educational context from which language classes can take advantage.

\section{A. The Reader-response Theory in Language Teaching}

It is strongly held by the advocates of the application of the reader-response theory in ELT that there is an apparent superiority in the advantages it can bring about in language teaching contexts in comparison to the traditional approaches (Carlisle, 2000; Hirvela, 1996). Having a long history of being practiced in language classes, the traditional approach devises the role of the sole conductor of the flows in the class to the teacher and it seems apparent that in such an atmosphere, and particularly while dealing with literary texts, students have the part of rather passive recipients, unable to exercise interpreting and analysing a given text with much creativity or diversity from what is aimed at by the teacher. On the contrary, in the reader-response theory, the act of reading is considered as an active, dynamic process, constantly prone to change in which readers are in charge of the creation and development of meaning. In such a context, the paramount role of readers in the process of meaning making of a text cannot be neglected or undermined by any means and thus, the interaction between the reader and the text is viewed as having utmost importance. This is the reason that in this approach to literature a variety of personal interpretations and analyses, based on not only the textual elements but also the reader's personal views, experiences and feelings, are welcomed (Diyanni, 2000; Kirszner and Mandell, 2001; Padley, 2006; Tyson, 2006). A fact strongly agreed on by psychologists is that learners can experience optimal learning while participating, and the reader-response approach provides a chance for the students' active involvement and full engagement in reading a text and class discussions on it.

However, in spite of its influential and innovative characteristics and promising perspectives, not many scholars or educators have realised the beneficial practicality of the reader-response theory in EFL contexts. This situation is either a result of this approach's yet unknown potentials or the aftermath of the language educators' reluctance to diverge 
from their routines. In either case, the vast domain of the reader-response theory is yet to be explored specifically in foreign language teaching.

\section{B. Purpose of the Study}

This study aims to introduce a reader-response approach to teaching English short stories to Iranian EFL learners. This is of considerable importance as EFL students must be granted with the chance to experience an enjoyable reading process in which reflection and expression of inner feelings and thoughts is made possible before, during and after the reading.

Being exposed to a reader-response approach to reading literary texts in the target language, the language learners could view reading English literature as a pleasurable and thought-provoking practice through which the horizon of their outlooks could be broadened. This was hoped to be achieved through using unlimited roots of self-expression, being exposed to the versatility of others' perspectives on a subject being discussed and getting to discover various touched emotions both within themselves and others.

In this study the researcher was interested in investigating probable differences in the reading comprehension, vocabulary acquisition the motivation for the further reading of English literature between students experiencing the reader-response approach in reading short stories and those going through the traditional method. Moreover, it was aimed to observe the possibility of students' giving aesthetic responses to literary texts without their reading comprehension being impaired.

\section{METHOD}

\section{A. The Participants}

Two intact English classes, one with 24 students and the other with 21 at Allameh Tabataba'i University with their ages varying between 18 and 24 provided the participants for the study. These were all students of the second academic semester, majoring in English translation and their performance on a reading comprehension quiz, a vocabulary test, and a motivation questionnaire were further evaluated.

These participants were from two different classes of Reading Comprehension courses being held at different hours and days of the week, going through the exact same academic ritual devoted to that course and both being taught by the same instructor. The students in neither of the two classes had been asked to read any English literary texts as a requirement for their previous courses and therefore, this was their first serious academic encounter with English literature.

The selected short stories to be read by the participants were supposed to be covered as a side-programme along with the other reading materials assigned by their own instructor. These short stories were all gone through with the researcher, being their instructor for 2 hours of the four-hour reading programmes of the week.

The students of these two classes were assured to be of a homogenous level of English proficiency and Reading Comprehension skill via a TOEFL reading comprehension test. Afterwards, one class was randomly chosen as the experimental group while the other as the control group, both directed by the researcher in the first two hours of the four-hour reading comprehension classes. These classes were then followed by a two-hour session instructed by their own instructor, concentrating on their routine reading programme.

\section{B. Instrumentation}

The following instruments were used to serve the purpose of the research study:

-The reading section of a TOEFL test to ensure that all of them would approach the chosen short stories with homogeneous levels of reading comprehension skill. The test consisted of five reading passages and the overall of 50 comprehension questions.

-A pre-reading questionnaire, containing 20 questions mainly in order to help have a general idea of what the participants' attitude towards reading literature in general, and English literary texts in particular was. This would also enable the researcher to compare any possible changes in the participants' attitude and motivation for further reading of English literature after the completion of the study. It must be mentioned that this questionnaire had been previously piloted on a group of undergraduate students of English translation. The reliability of it was calculated as being (.89), a high reliability index for a questionnaire and the validity verified by asking some of the researchers' professors' professional opinions.

-A Vocabulary quiz, consisting of 80 words, all extracted from the short stories that were supposed to be read during the course. The vocabulary items were chosen to ensure that none of the students were already acquainted with any of them. In this case, after the completion of the study, the acquisition of the vocabulary items could directly be attributed to the reading of the short stories. Words with which the students were familiar were consequently excluded from the researcher's consideration and the post-test.

-A Post-experiment vocabulary quiz, consisting of 50 items, designed to check the vocabulary acquisition of participants after reading the short stories. All the vocabulary items were chosen from the six short stories covered during the study and the questions were divided into different forms, varying from multiple-choice questions and fill in the gaps to the giving the meaning of the words in translation. 
-A Reading Comprehension exam in which ten questions were asked concerning the six short stories focused on throughout the experiment. These questions were designed to evaluate the participants' overall comprehension of the short stories. All short stories were taken into account and the students were not informed of this upcoming exam, in order to prevent any pre-exam reviewing or revising.

-A Post-reading Questionnaire, with 20 questions similar to the pre-reading questionnaire with a slight modification, designed to observe any probable changes in the participants' attitudes towards English literature and their motivation for the further reading of English literary texts.

\section{The Short Stories}

After reviewing several collections of English short stories, six short stories were chosen by the researcher in order to be covered in both the experimental and control groups throughout the course. These short stories were all selected as they were supposed to evoke a suitable amount of emotional response and were promising to provoke students to express their versatile opinions and interpretations of the short stories.

The short stories, in the order of their presentation were: "The chaser" by John Collier, "The Story of an "Hour" by Kate Chopin, "A Jury of Her Peers" by Susan Glaspell, "The Use of Force” by William Carlos Williams, "The Necklace" by Guy de Maupassant, and "The Misery" by Anton Chekov. All the above stories were originally written in English, with the exception of The Necklace and The Misery, the former translated from French and the latter from Russian into English.

Taking numerous short stories in English into consideration, the researcher selected the chosen six, hoping that because of their plots, characterisation, suspense and ironies they could attract the attention of the students and drive them into the free expression of their personal interpretations and opinions. Moreover, these short stories were short enough to be read in a one week's time by the students and discussed in the limited class time. The themes were also framed in a manner with which participants could relate and interact according to their ages and status.

It is worth mentioning that the selection of short stories rather than plays, novel or poetry was first due to the fact that, regarding the consideration of time constraint, reading short stories seemed more practical and possible and second, the genre was generally considered to be easier for the students to go through in comparison with poetry, for example, as it has been the participants' first serious encounter with English literary works.

\section{THE DESIGN}

In this study, the researcher desires to investigate the differences in motivation, reading comprehension skill and vocabulary acquisition of two intact groups after the process of treatment. According to Best and Kahn (2006), because random assignment to the participants in the two groups was not applied, the students falling in each of these groups were determined prior to the beginning of the experiment, and they were naturally assembled, a quasi-experimental design was implemented.

\section{THE PROCEDURE}

As aforementioned, a reading part of a TOEFL test was administered among them with the objective of measuring the students' degree of homogeneity and afterwards the students whose scores were one standard deviation below and above the mean were selected as those whose performances were of the interest of the researcher. There remained the total of 42 students, 23 in the experimental group and 19 in the control; the excluded members were not considered for data analyses.

As the study of the vocabulary acquisition and motivation for reading English literature in the participants were also other concerns of the researcher, before introducing the first assigned short story to the student the vocabulary quiz was taken and in addition to it, the pre-reading motivation questionnaire distributed amongst the students.

In both the experimental and control groups the short stories were given to the participants not all together, but one at a time. They were asked to read a short story for the following session. In order to facilitate the reading process for the students and save them the time and energy spent on looking up new vocabulary, a word list was accompanied by each short story with the definition of all unfamiliar words on it. At the end of each session, the story to be read for the upcoming class, together with its vocabulary list, was distributed among the students.

\section{A. Procedure in the Control Group}

In this group the traditional method of teaching literature was pursued and the main focus of attention here was the writer's intention of writing the story. Therefore throughout the class discussions of the stories the instructor was the centre of the class, directing students to reach the one supposedly "correct" interpretation of the story. The debate started with the researcher asking about the summary of the story, followed by analysis of the characters, themes and other literary aspects of the story. Participation of all students was called upon, asking them to express what they thought about the domineering themes, character development, and the "message" of the story; however, it was the instructor who stated the final correct interpretation and explanation. 
After each phase of the discussion, the researcher elaborated on the matter being discussed, for example characters, themes, setting, point of view, irony, tone and symbolism. She emphasized what has allegedly been the author's intended meaning and message lying beneath every aspect of the story.

During the class, particular sections of the story were brought to attention by the researcher to support and validate the views expressed, by conveying the fact that there is only one possible interpretation of specific passages of the story. In this class, the students were rather passive recipients of the teacher's instructions without having the influence to affect or change the path of instruction determined by the teacher.

\section{B. Procedure in the Experimental Group}

In the experimental group, the reader-response approach to reading short stories was implemented. The crucial difference this group entailed was that the complete versions of the short stories were not given to the students; this was done in a way that the ending was not apparent, something that created the opportunity for the students to express their own predictions about the upcoming events or plausible changes in the path of the stories.

In this class the instructor took the role of a conductor only, controlling the turn takings, posing thought provoking questions and initiating discussions. Students voiced their versatile opinions about the main characters of the story, whether they liked them or not and if they knew anyone with familiar personality traits in their real lives. The instructor asked participants about the mood or feeling the atmosphere of the story created in them and asked them to read aloud specific passages from which these feelings were evoked in them. Another question was whether they would have chosen a different setting, ambience or environment to write the same story had they been the author. The students were also asked to talk about any similar life experience they had had; and then, they proposed their idea of what the ending to that story would be.

Overall, the main debates were carried on amongst the students, expressing their internal thoughts and feelings to a single aspect and reacting to others' viewpoints. The questions or statements put forward by the researcher were meticulously chosen in order to fuel the free, non-restricted overflow of the participants' reactions, ideas and inner-most feelings.

At this point, the final section of the story was given to the participants and they were given time to read it silently. Afterwards, the class discussion was directed towards the expression of the students' reactions to the ending, how they favoured it or if they would have chosen a different ending for the story. Any probable changes in their prior interpretations or feelings towards characters or event were also talked about, reflecting the fact that anyone's initial approach to various aspects of a story could undergo a gradual transformation as readers move on in the story and is shaped fully only when they reach the ending.

After the completion of discussions on all six short stories, the reading comprehension test based on the stories and a vocabulary quiz constructed from the vocabulary items existing in the word lists of all short stories were administered. This was done in order to compare any probable difference in the experimental and control groups, resulting from different approaches to teaching the short stories implemented in the two classes. A post-reading questionnaire was also prepared, containing almost the same questions of the pre-reading questionnaire with a slight modification. It aimed to take into account any changes in the participants' motivations for the further reading of English literature, and to compare the impact each teaching methodology had had on the attitude and approach of the students to reading English literature.

\section{RESUltS}

After the implementation of the study and the collection of data, an independent t-test was run to compare the means scores of the control and experimental groups on the Pre-experiment Reading Comprehension test. Based on the results obtained, it was concluded that there was not any significant difference between the experimental and control groups' reading comprehension ability prior to the administration of the treatment.

An independent t-test was run to compare the means scores of the two groups on the Pre- Reading questionnaire. The mean scores for the control and experimental groups were 35.60 and 32.94 respectively. These results indicate that the control and experimental groups are selected from the same population of students with no marked difference between their variances. The result of the evaluation of the pre-experimental questionnaire displayed no significant differences between the control and experimental groups' mean scores on the motivation questionnaire; this indicated that the two groups' motivations were almost at the same level and that any probable discrepancy in the results of the postexperimental questionnaire can be directly attributed to the difference in teaching approaches.

An independent t-test was run to compare the means scores of the control and experimental groups on the PostReading questionnaire. The descriptive statistics for the two groups are presented in Table 1. The mean scores for the control and experimental groups are 7.78 and 37.16 respectively. 
TABLE 1:

DEsCRIPTIVE Statistics Post- READING Motivation QuestionnAire

\begin{tabular}{|l|l|l|l|l|l|}
\hline Group Statistics & GROUP & N & Mean & Std. Deviation & Std. Error Mean \\
\hline \multirow{2}{*}{ Post Reading Questionnaire } & EXPERIMENTAL & 19 & 37.789 & 3.224 & .7397 \\
\cline { 2 - 7 } & CONTROL & 18 & 37.166 & 2.895 & .6824 \\
\hline
\end{tabular}

Based on the results, it was concluded that there was not any significant difference between the experimental and control groups' mean scores on the post-experiment motivation questionnaire. Thus, revealed that the students who read literature using the reader-response approach were not more motivated to read literature in the target language than those trained by traditional methods. In other words, the reader-response approach did not improve the Iranian EFL students' motivation to read literature in the target language.

In order to compare the means scores of the control and experimental groups on the vocabulary retention test an independent t-test was run. Below comes the descriptive statistics for the two groups presented in Table 2 . The mean scores for the control and experimental groups are 44.31 and 43.52 respectively.

TABLE 2:

DESCRIPTIVE STATISTICS VOCABULARY RETENTION THROUGH THE READER-RESPONSE APPROACH

\begin{tabular}{|l|l|l|l|l|l|}
\hline Group Statistics & GROUP & $\mathrm{N}$ & Mean & Std. Deviation & Std. Error Mean \\
\hline \multirow{2}{*}{ Vocabulary Retention } & EXPERIMENTAL & 22 & 44.318 & 3.859 & .822 \\
\cline { 2 - 7 } & CONTROL & 19 & 43.526 & 4.101 & .940 \\
\hline
\end{tabular}

Based on these results, it could be concluded that there was not any significant difference between the experimental and control groups' mean scores on the vocabulary retention test. Thus it was found out that the vocabulary retention of the students who read literature using reader-response approach did not exceed more in comparison to those experiencing literature with traditional methods. In other words, the Reader-Response approach did not improve the Iranian EFL students' vocabulary mastery in the target language.

Moreover, an independent t-test was run to compare the means scores of the control and experimental groups on the post-experiment reading comprehension test. The descriptive statistics for the two groups are presented in Table 3 . The mean scores for the control and experimental groups are 8.33 and 7.52 respectively.

TABLE 3:

DESCRIPTIVE STATISTICS POST-EXPERIMENT READING COMPREHENSION TEST

\begin{tabular}{|c|c|c|c|c|c|}
\hline \multicolumn{6}{|l|}{ Group Statistics } \\
\hline & GROUP & $\mathrm{N}$ & Mean & Std. Deviation & Std. Error Mean \\
\hline \multirow{2}{*}{$\begin{array}{l}\text { Post-Experimental Reading } \\
\text { Comprehension Test }\end{array}$} & CONTROL & 18 & 8.333 & 1.644 & .3877 \\
\hline & EXPERIMENTAL & 23 & 7.521 & 1.728 & .3604 \\
\hline
\end{tabular}

Based on these results, not any significant difference between the experimental and control groups' mean scores on the post-experiment reading comprehension test was revealed. Thus it was concluded that the Iranian EFL students using reader-response approach could indeed give aesthetic responses to English short stories without sacrificing the comprehension of the story. To put it in other words, the Reader-Response Approach did not impair the reading comprehension ability of the Iranian EFL students.

\section{DISCUSSION AND CONCLUSIONS}

As earlier mentioned, the major focus of this study was to observe, describe and interpret how Iranian EFL students respond to a literary text and how different their responses would be in the traditional and the reader-response approaches.

The aim of this research was to take into consideration the readers' reading comprehension, vocabulary acquisition and motivation for the further reading of literature in the future and to compare the findings in the traditional and the reader-response approaches. Based on the findings of the study, several conclusions can be drawn upon, below is the thorough explanation of each.

The first concern of the researcher in this study was to investigate the probability of any influence the application of the reader-response theory could have on the improvement of students' motivation for the further reading of literature. 
The results of the performed statistics revealed that the reader-response approach cannot significantly improve the students' motivation for reading English literature. It is, however, noteworthy that the effect the reader-response approach to reading literary texts might have on the enhancement of students' motivation to read literature in the target language can be influentially different if tested over a longer period of time.

Moreover, neither of the two groups had any experiences with English literary texts in an academic context prior to the experiment. Hence, the superiority of the reader-response theory to the traditional method in improving students' motivation can indeed be proved if this approach is used with students with a prior experience of reading literary texts through other approaches.

The second matter this study sought to find an answer to was whether there is any difference between the amount of vocabulary acquisition in the students who read the short stories with a traditional approach and those taught with a reader-response tendency.

It is important to note again that neither of the two groups of control and experimental were exposed to a direct teaching of vocabulary, nor have their attentions been explicitly directed towards specific vocabulary items. As the matter of fact, the mere difference between the two approaches of teaching that could be somewhat relevant to the acquisition of vocabulary would be the concurrent demand from the students of the experimental group to point out and read aloud specific lines or passages of the story by which particular responses and reactions of them were aroused. This way there would be an opportunity in which readers could have extra, however subconscious, encounters with passages containing some of the chosen vocabulary items.

The conclusion of the carried out statistical procedures revealed that the application of the reader-response approach in reading literary courses did not lead to a noteworthy improvement in the acquisition of vocabulary items in the target language.

Thus, there is not enough evidence that can lead educators to the selection of the reader-response approach to reading literature over the traditional method if the sole or main objective of a course is the improvement of the students' mastery of vocabulary items in the target language.

The examination of the participants' written responses to comprehension questions based on the six taught short stories aimed at evaluating and comparing the degree to which readers had comprehended the reading passages. Another significant concern in this study was the investigation in the possibility of readers giving aesthetic responses to a literary text without risking the comprehension of the text to be sacrificed.

In order to receive adequate knowledge for drawing such a conclusion, different approaches were conducted in classes taught with traditional and the reader-response methods. While in the traditional method short stories were approached by the teacher as the director, in the reader-response method the cooperation of the students in the process of interpretation of the stories led to various, at times quite contradictory, interpretations and analyses of a single short story.

In the control group, in which the traditional method of teaching short stories was applied, the students were directly directed towards accepting one unified interpretation of the story, namely the correct or most agreed upon analysis of it. In this case readers had no chance to relate the sequence of events, characters or the current atmosphere of the story to their personal experiences or to study any factor of the story by taking them into the zone of their inner feelings. It is, therefore, apparent that all students were taught to acquire very close, if not entirely identical, interpretations of the read short story.

On the other hand, being taught by the reader-response approach, the experimental group viewed and analysed the given short stories by practicing a far more active involvement in the stories. In this case, at times the readers responded to the short stories aesthetically, personalising the themes, moods and atmosphere of the story. In doing so, more weight was placed on the discussion of the moral of the stories. Throughout the process of reading the short stories, the readers were provided with a chance to associate ideas, characters and incidents to their personal lives, engaging the knowledge, emotions and experiences they had prior to the experiment.

In assessing the written responses of the students of both classes to the reading comprehension questions and comparing the outcomes by running an independent t-test, it came out that there was no significant difference between the reading comprehension results of the control and experimental groups. This led us to believe that the students could in fact give aesthetic responses to literature without endangering the comprehension of it.

It is apparent from the findings that students trained with a reader-response approach to reading literature are able to comprehend a literary text as fully as those experiencing the conventional method of the traditional approach. This indicates that while having full engagement and involvement in the literature under consideration, relating and connecting it to their most personal experiences and worldviews and attaching emotions to their interpretation of the text, the readers can still have quite acceptable understanding of the text.

Participants in the control group passed almost the same path the teacher guided them through, and as previously mentioned there was little space left for them to exercise individual varied interpretations of the text. Whereas, students participating in the reader-response group each formed and gradually developed their own personal analysis and interpretation of the text, resulting in a multitude of dimensions and aspects of the story. 
The statistical analysis revealed that while the application of the reader-response approach to teaching short stories did not significantly improve the comprehension skill of the students in comparison with the traditional method, yet it displayed an equal level of understanding of a literary text in students of both groups.

This conclusion well indicates that the long used traditional approach to teaching literature can securely be replaced by the promising reader-response approach without endangering the adequate comprehension of a text. Being exposed to a reader-response method of teaching literature, EFL readers can enjoy a free atmosphere of self-expression, the experience of emotional and attitudinal involvement in the vast world of literature and a journey in the endless realm of interpretations.

The most fundamental concern of this study was to examine the extent to which the reader-response theory and the practices associated with it can be applicable in Iranian EFL classes. A very important dimension of the target of the researcher was the observation of how this theory would succeed if practiced in EFL reading classes with literary texts being justified alternatives for ordinary conventional texts.

A few parameters can be pointed out, assumed by the researcher as being effective in the formation of the study's findings, below comes a short notification.

This study was carried out during eight consecutive sessions of 1- hour and thirty minutes each. It is noteworthy that the first and last sessions were devoted to the accumulation of necessary data and the administration of pre-experimental and post-experimental tests and questionnaires.

As students of both the experimental and control groups were sophomores of English Language Translation they had not had any academic encounters with literary texts at university prior to the experimentation. Having pointed out this fact, it seems obvious that to students of the experimental group, the reader-response theory by which they were instructed was a very new and exciting experience they were quite unfamiliar with. The entire instruction they had always been exposed to throughout their education was based on the traditional method. In this context, most naturally the students of the control group felt more at their comfort zone as the majority of practices and the flow of discussions were all in the same format they were used to.

Due to the pressure of the time constraint faced with by the researcher, the students could not be given sufficient time and opportunity to adjust to the innovative, newly introduced approach. Moreover, as their major of choice had been English Translation, it seems just normal that they were not as keen on or drawn to reading English literature by nature as can be expected from students of English literature.

However, it was noticed and vividly felt by the researcher that as the sessions of the class went by there appeared a more welcoming, more eager involvement in the approach on the part of the participants. With all intimidating factors being dimmed into the excitement of heated discussions in the class, the students clearly felt more comfortable expressing their innermost feelings and stating their personal viewpoints.

Still, in the context of university courses and with these students of English translation, the mentality of the majority of them favoured the mere passing of the course with an acceptably good mark and subconsciously, even students of the experimental group shifted their attention to what could be expected in the conventional recurring system of university quizzes. In this mood, it is apparent that the optimal devotion on the part of the participants to the practices of the reader-response could not be expected.

Furthermore, reading short stories was only a part of the requirements of this course, because as determined by their main instructor, the participants had to go through a textbook, mostly focusing on non-literary articles. This also, takes away the full concentration and attentiveness of the participants in adapting their reading literature with the unconventional approach of reader-response, as desired by the researcher.

Having mentioned all the above facts, it must be wholeheartedly emphasised that the researcher found the experimental experience a wholly rewarding and successful one. It must be concluded that the researcher witnessed the students' expression of their great excitement about the new intriguing experience and how they looked forward to having more literary texts incorporated in their curriculums.

\section{PEDAGOGiCAl IMPLiCATIONS}

Numerous strongly supported advantages of placing literature in language pedagogies have been called upon by many EFL educators and theoreticians (Carter \& Long, 1991; Duff \& Maley, 1991; Lazar, 1993; 1994). In addition to all the aforementioned, the findings of the present research can also inspire language educators to invite literature, in general, and reader-response theory of teaching it in particular, into their language teaching curriculums.

This study was implemented in a reading course in which non-literary texts and articles are customarily worked on. It is generally believed by the instructors that non-literary texts are written in a much less complicated language in comparison with the literary ones, and thus practicing reading them is a reasonably effective strategy in order to prepare students for the higher complexity of literature they would encounter in the following semesters.

While this belief has been widely accepted and examined in reading courses at university levels in Iran, it is beneficial to highlight some of the spectacular advantages of placing literature, even in the general reading courses of EFL students.

Students of both control and experimental groups in this study had the chance to experience both non-literary texts and short stories as consisting parts of their reading course requirements. The textbook they had to cover throughout the 
course-taught by their own instructor- consisted of general or scientific articles and texts, previously devised for the reading courses at university levels.

The six selected short stories brought to the class had all been meticulously chosen by the researcher as being appropriate materials for both the proficiency level of the participants and containing discussable themes and moods. In this case the students did not face any considerable difficulties while reading the stories, nor did they find the stories contrastingly abstract according to their own cultural, religious, or historical codes.

The stories had all very general relatable themes with which the students were not totally unacquainted. Therefore, the discussions and debates on the short stories were triggered easily by some initiating questions on the part of the researcher and the rest was left to the enthusiasm of the appealed students.

It can be concluded from all the above mentioned points that if dedicated and determined to use literature in EFL classes, language educators shall without doubt find appropriate literary texts, in harmony with their students' level of proficiency, interests and needs. Having done that, language instructors can create a non-threatening ambience in which each and every individual finds the themes of the story discussable and relatable and can, hence, express his own viewpoint and feelings about them freely.

It was reported to the researcher by a multitude of participants in both experimental and control groups that they were extremely thrilled by and content of reading short stories in their reading course and that they were highly motivated to participate in all class discussions as the result of their familiarity with the themes of the stories and the existence of general events and atmospheres.

They found short stories far less tiresome and monotonous than the scientific, non-literary texts they were used to reading in their courses prior to the experiment. Moreover, many students claimed that the short stories kept them thinking and exploring even after the class was over and that the chain of events and characters held their minds captivated. This well indicated the influential and effective nature of literature not only in the enhancement of general English but also in developing the potentials of students' mentality and power of critical thinking.

It is strongly held by the advocates of reader-oriented theories and the researcher as well, that this approach to teaching literature outweighs the routines of traditional methods of working on literary texts. This view can be generalised to teaching in EFL classes as well, whether the objective of the instruction is teaching literature or the expansion of language proficiency in learners via reading the target language's literature.

In the experimental group, instructed by the reader-response approach, a number of different questions were prepared, each of which addressing a specific aspect of the story, the characters or the themes in order to mine out the engraved sparkles of thought and emotion in the students.

In such an environment, the students were given clues to assist them in stating their ideas and touched upon feelings without the probable intimidations that could be felt in classes run by the traditional method. In reader-response approach due to the fact that there is no single correct interpretation or analysis of a piece of literature, the diversity and versatility of opinions and criticisms are welcomed and appreciated.

It is advisable to apply this method in classes focusing on literary texts in order to eliminate the usual drawbacks the traditional method can bring about, such as the fright of being criticised for offering a less than accurate interpretation.

A further advantage of reader-response approach over the traditional method is that in the former, readers are required to read the literary text in specified sections and, thus, they are asked to share their understandings, interpretations and predictions after each section. In such a case, the students can maintain dynamic and attentive roles in the gradual and step by step process of meaning making.

The students can share their surprises, favouritisms, likes and dislikes and all feelings and ideas of the same nature. As a result, with the dominance of the reader-response approach in a class, not only is there a friendly, warm and enjoyable atmosphere created, but the students also can listen to and think about other interpretations and both learn the appreciation of differences in opinions and the art of critical thinking.

In Iranian EFL classes, as in many other countries, students are trained to agree on a single interpretation, usually provided by the instructor. Implementing the reader-response approach in EFL classes can enhance many qualities in the learners far beyond the mere improvement of their language proficiency. This method can alter our students into better and more skilled readers, equipped with broader views and more appreciative of diversity in tastes and worldviews.

While in the traditional method usually the comprehension of a literary text alone suffices, in the reader-response approach constant and dominant attention is focused on aesthetic reading of literary texts. Therefore, equal significance is attached to and devised for both comprehension and active transaction with the text. However, educators should be alarmed to beware of pursuing either of the extremes; attaining a wholly comprehension-based or totally response-based classroom.

\section{SUGGESTIONS FOR FURTHER RESEARCH}

The present study opens up a few possibilities for those interested in the implementation of literature in EFL. The first suggestion to language educators or researchers is to replicate the design of this study in different courses and with different literary genres. This way, the practicality and efficacy of the reader-response method in teaching different genres of literature can be studied and compared. 
Another suggestion would be to increase the allocated time to the implementation of this approach in order to achieve optimal result. Being used to the traditional method of reading literature, the students might be benefitted from being exposed to the newly introduced approach of reader- response. In this case they are given the opportunity and adequate time to become familiar with and used to the requirements and practices of the reader- response theory and thus play a more active and influential part in it.

Moreover, when provided with more time, instructors can devise more group activities and pair works to place responsibility on groups rather than individuals. This way, each individual will be given the chance to express his feelings and ideas in pair or groups at first, and then gradually share views with the whole class, a technique that will logically reduce strains of stress and self-consciousness.

One other suggestion is to study the discrepancy between the responses and reactions of male and female students and to observe the degree they welcome or adapt themselves to the reader-response theory. The parameters studied in this research, namely reading comprehension, vocabulary acquisition and motivation for further reading of literature can be separately investigated and compared among male and female participants.

This study was performed with groups of students who had not had academic encounters with literary texts prior to the experiment and their major had not been English literature. In further researches, it is advisable to conduct classes of students majoring in English literature or those who have already had experience in reading the target language literature. Instructing his class with reader-response theory, a researcher will have the privilege of gaining experiences in teaching literature via both the traditional and the reader-response methods which provide the chance of comparing the efficiency and success of both according to his students' needs and interests.

\section{REFERENCES}

[1] Best, J. W. \& Kahn, J. V. (2006). Research in education. (10th ed.). USA: Pearson Education Inc.

[2] Brumfit, C.J. \& Carter, R.A. (Eds). (1986). Literature and language teaching. Oxford: Oxford University Press.

[3] Carlisle, A. (2000). Reading logs: an application of reader-response theory in ELT. ELT Journal. 54 (1): 12-19.

[4] Carter, R. \& Long, M.N. (1991). Teaching literature. London: Longman Group Ltd.

[5] DiYanni, R. (2000). Literature: reading fiction, poetry, and drama. New York: McGraw-Hill Higher Education.

[6] Duff, A. and Malay, A. (1991). Literature. Oxford: Oxford University Press.

[7] Hirvela, A. (1996). Reader-response theory and ELT. ELT Journal, 50 (2), 127-134.

[8] Kirszner, L. G. \& Mandell, S. R. (2001). Literature: reading, reacting, writing. $4^{\text {th }}$ ed. USA: Harcout College Publishers.

[9] Lazar, G. (1993). Literature and Language Teaching: a guide for teachers and trainers. Cambridge: Cambridge University Press.

[10] Lazar, G. (1994). Using Literature at lower levels. ELT Journal, 48 (2): 115-124.

[11] Maley, A. (2001). Literature in the language classroom. In Carter, R. and Nunan, D. (Eds.). Teaching English to speakers of other languages. Cambridge: Cambridge University Press.

[12] McRea, J. (1991). Literature with a small 'l'. MEP/Macmillan, Basingstoke.

[13] Padley, S. (2006). Key concepts in contemporary literature. New York: Palgrave Macmillan.

[14] Spack, R. (1985). Literature, reading, writing and ESL: Bridging the gaps. TESOL Quarterly, 19 (4), 703-725.

[15] Tyson, L. (2006). Critical theory today: A user-friendly guide. $2^{\text {nd }}$ Edition. New York: Routledge.

[16] Widdowson, H.G. (1975). Stylistics and the teaching of literature. London: language Group Ltd.

[17] Widdowson, H.G. (1984). Explorations in applied linguistics. Oxford: Oxford University Press.

[18] Widdowson, H.G. (1992). Practical stylistics. Oxford: Oxford University Press.

Sarvenaz Khatib was born in October 11, 1984 in Tehran-Iran. She holds a B.A. in English Literature and an M.A. in TEFL both from Allameh Tabataba'i University, Tehran-Iran. She has been teaching English at various levels of proficiency since 2002 and is currently a lecturer at Allameh Tabataba'i University, teaching literature courses to undergraduate students. 